Source: Werner Ulrich: "The quest for competence in systemic research and practice," Systems Research and Behavioral Science, Vol. 18, No. 1, 2001, pp. 3-28.

This prepublication version (C) 2000 by W. Ulrich - All rights reserved. Non-commercial distribution and citation of the prepublication version are permitted on the condition that proper reference is given to the published version (C) 2001 John Wiley \& Sons, Ltd. To allow accurate citation, original page breaks are indicated in the text in brackets, whereby [II N ] means that at this place, page $\mathbf{N}$ is beginning in the original version.

\title{
The Quest for Competence in Systemic Research and Practice
}

\section{Werner Ulrich*}

University of Lincolnshire and Humberside, Lincoln, UK

How can we develop competence in research and professional practice? This essay tries to answer the question from the perspective of critical systems thinking, that is, through an approach that aims to promote reflective research and practice. The paper originated in discussions on the nature of research, with research students and professionals from different fields - among these the domains of business and public management, operational research and management science, social planning and evaluation research, public health, poverty research, social work and social policy, environmental research, city and regional planning, adult education and civic studies. With its publication the author hopes to encourage a wide readership of research students, researchers, and professionals in these and other fields of practice who wish to clarify their personal notion of competence. The essay addresses them in a direct and personal way.

Keywords professional competence; professionalism; reflective practice; research; systems research; critical systems practice; critical systems thinking; critical systems heuristics

Correspondence to: Werner Ulrich, Sichelweg 41, CH-3098 Schliern, Switzerland.

E-mail: wulrich@gmx.ch. 


\section{INTRODUCTION}

'We understand only when we understand the question to which something is the answer.' (Gadamer, 1975, p. 356, with reference to Collingwood, 1946). Hence, if we want to understand what it means to be 'competent' in any field of study, we need first to ask what sort of question we are trying to answer through such competence. With special regard to systems thinking, what is the fundamental question to which systemic research and practice should respond? That is, if systems thinking is (part of) the answer, what is the question?

In the search for this question it should be clear that systems thinking is of interest more as a means for promoting personal competence in various fields of study than as a field of study for its own sake. The primary concern is competence, not systems. Furthermore, it should be equally clear that increasing one's competence requires a sustained personal effort at learning and growth. Since every reader is a unique person with different skills, interests, and talents, it is obvious that needs for personal learning and growth will differ. Some readers will wish to deepen their expertise as (future) researchers or professionals, for example by acquiring some specific skills in research methodology and systems thinking. Others may feel a need to strengthen their capabilities for more general purposes. Perhaps you, the reader, [||4] already feel confident about your professional training and experience but would like to become a more reflective professional, or even a more mature person in general. The quest for competence is a very personal undertaking indeed. As a reader, you should thus not expect this essay to offer you a specific formulation of your fundamental question, that is, the question that might guide you in your personal quest for competence. I cannot formulate this question for you, only at best help you in finding your own central theme. My goal, therefore, is merely to guide you toward a few possible topics for reflection, towards meaningful questions to ask yourself.

The paper also offers some considerations as to how you might deal with these topics, but please bear in mind that the purpose is simply to turn your attention to some questions that you might find relevant and not to give you the answers; that is to say, I do not claim that the considerations I offer are the only possible ones or even the only valid ones. I offer them as examples only. Their choice appears relevant to me at this particular moment in my academic and personal journey; even if some of them should prove helpful to you at the specific moment you have reached in your own journey, you will need to pursue your quest for competence in your own unique way. Nobody has a monopoly or a natural advantage in knowing what are the right considerations for you. Everybody is entitled to have differing views on what the quest for competence means. Contrary to academic custom, the game for once is not to be right but only to be true to yourself.

As a last preliminary remark, a note concerning style. In the discussions with research students and professionals which inspired this paper, I found that research students often see questions and difficulties that established professionals tend to lose sight of as they become used to research conventions and routine procedures in their fields, and I have therefore chosen to address my readers as 'research students'. But of course the paper aims to reach established researchers and professionals, too. If you consider yourself one of these two, you may wish to read 'research student' as meaning 'student of competence' - for students of competence, I take it, we all remain throughout our lives. 


\section{THE BURDEN OF BECOMING A 'RESEARCHER'}

As research students you are supposed to do 'research'. Through a research project and a dissertation you have to prove that you are prepared to treat an agreed-upon topic in a scholarly manner, in other words, that you are a competent researcher.

Not surprisingly then, you are eager to learn how to be a competent researcher. But I suspect that few of you are quite sure what precisely is expected of you. Hence the job of 'becoming a competent researcher' is likely to sound like a tall order, one that makes you feel a little uncomfortable, to say the least. What do you have to do to establish yourself as a 'competent' researcher?

From what you have been told by your professors, you have probably gathered that being a competent researcher has something to do with being able to choose and apply methods. Methods, you have understood, should be appropriate to the problem you are dealing with and should help you to produce findings and conclusions that you can explain and justify in methodological terms. That is to say, you should be able to demonstrate how your findings and conclusions result from the application of chosen methods and why methods and results are all valid.

Of course that makes you worry about which methods you should apply and how to justify your choices. It really seems to be an issue of choice rather than theory. There are so many different methods! The choice appears to some extent arbitrary. What does it mean to be a competent researcher, in view of this apparent arbitrariness? You may have turned to the epistemological literature for find help, but what you have found is likely to have confused you even more. The prescriptions given there certainly seem abstract and remote from practice, apart from the fact that the diverse prescriptions often enough appear to conflict with one another.

As a second difficulty, once you have chosen a methodology and start to apply it, you will at times feel a strong sense of uncertainty as to how to apply it correctly. Methods are supposed to give you guidance in advancing step by step. You expect them to give you some security as to [\|5] whether you are approaching your research task in an adequate way, so as to find interesting and valid answers to your research questions. Instead, what you experience is confrontation with problems and doubts. There seem to be more questions than answers, and whenever you dare to formulate an answer, there again seems to be a surprising degree of choice and arbitrariness. Whatever answers you formulate seem to be as much a matter of choice as the method you have used and how exactly you have used it.

Given this burden of personal choice and interpretation, you may wonder how you are supposed to know whether your observations and conjectures are the right ones. How can you develop confidence in their quality? How can you ever make a compelling argument concerning their validity? And if you hope that in time, as you gradually learn to master your chosen method, you will also learn how to judge the quality of your observations, as well as to justify the validity of your conclusions, yet a third intimidating issue may surface: how can you ever carry the burden of responsibility concerning the actual consequences that your research might have if it is taken seriously by other people, for example by people in an organization whose problems you study, if they accept your findings or conclusions and implement them in practice? 
As a fourth and last difficulty that I want to mention here, your major problem may well be to define 'the problem' of your research, that is, the issue to which you are supposed to apply methods in a competent fashion. This is indeed a crucial issue, but here again the epistemological and the methodological literature is rarely of help. Its prescriptions seem so remote from practice. Moreover, it is questionable whether we should let our methods define the problem. A definition of a research problem should tell us something essential about the object of research; that is, it should be more a function of live, social practice (including the practice of research, if the issue is research itself) than a function of the methods you happen to know. I will come back to this issue of the 'primacy of practice' in a later section.

A lot of questions to worry about, indeed! But didn't we just say that without questions there is no understanding? So take your questions and worries as a good sign that you are on your way toward understanding. Let us explore together where this way might lead you. One thing seems certain: if you do not try to understand where you want to go, you are not likely to arrive there!

\section{THE DEATH OF THE EXPERT ${ }^{1}$}

Sometimes it is easier to say what our goal is not, rather than what it is. Are there aspects or implications of 'competence' that you might wish to exclude from your understanding of competence in research? Certainly.

For instance, in what way do you aim to be an 'expert' on systems methodologies (or any other set of methodologies), and in what way do you not want to become an 'expert'? To be 'competent' in some field of knowledge means to be an expert, doesn't it? The role that experts play in our society is so prominent and seemingly ever more important that many of their assumed roles immediately come to our mind. To mention just three: experts seem to be able to make common cause with almost any purpose; most of the time (except when they are talking about something we happen to be experts in) experts put us in the situation of being 'lay people' or non-experts (i.e., incompetent?); experts frequently cease to reflect on what they are doing and claiming. So what role would you rather not play as a competent researcher? In what way would you rather not claim expertise, that is, limit your claims to expertise? Where do you see dangers of ceasing to be self-critical?

Ceasing to be self-critical, with the consequent risk of claiming too much, is unfortunately very easy. So many aspects of 'expertise' or 'competence' call for self-critical handling! Basically, we [ $\| \mathbf{6}]$ do not want to obscure or even disregard the limitations of our methods - 'methods' in the widest possible sense of any systematically considered way to proceed - on which our competence depends. The limitations of a method are among its most important characteristics, for if we are not competent in respecting these limitations, we are not using the method in a competent manner at all. From a critical point of view, no human method should ever be assumed to be sufficient for dealing with all aspects of a problem; only

\footnotetext{
White and Taket (1994) have used this phrase before me. They are among the few authors who consider their personal professional practice in this way, and I am therefore pleased to call the reader's attention to their discussion. My discussion here is independent of theirs, though, since at the time of writing the present essay I was not aware of their work.
} 
gods (perhaps) know omnipotent methods. Hence, one of the first questions we should ask about every method concerns its limitations. Technically speaking, the limitations of a method may be said to be contained in the theoretical and methodological assumptions that underpin any reliance on it. Some of these may be integral to the specific method we use, in the sense of being built into that method; others may arise rather through the imperfect way we use it or the inappropriate purpose for which we use it.

Perhaps an even more basic assumption is that the expert, by virtue of his/her expertise, has a proper grasp of the situation to which s/he wants to apply his/her expertise, so that s/he can properly decide what method is appropriate and hence this choice can then ensure valid findings and conclusions. Experts often seem to take such assumptions for granted, or else tend to cover them behind a façade of busy routine.

To the extent that we are insensible to these assumptions, they threaten to become sources of deception. We ourselves may be deceived as researchers, but inadvertently we may also deceive those who invest their confidence in our competence. There need not be any deliberate intention to deceive others on the part of the researcher; it may simply be his routine which stops him from revealing to himself and to other concerned persons the specific assumptions that flow into every concrete application of methods. Even so, this is probably not what you would like to understand by 'competence'.

The earlier-mentioned questions and doubts that plague many a research student are then perhaps a healthy symptom that your research competencies have not yet reached the stage of routine where this lack of reflection threatens. This danger is more of a threat to established researchers who have already become recognized as experts in their field. Although some degree of routine is certainly desirable, we should not confuse it with competence. Routine implies economy, not competence.

When experts forget this distinction, they risk suffering the silent death of the expert. It seems to me at times that in our contemporary society, the death of the expert has taken on epidemic dimensions! We are facing an illness that has remained largely unrecognized or incorrectly diagnosed, perhaps because it causes an almost invisible death, one that often enough is hidden by the vigorous and impressive behaviour patterns of those who have developed the disease.

There is a second cause of the death of the expert that we must consider. Even if a researcher remains thoroughly aware of the methodological and theoretical underpinning of his or her competence and makes an appropriate effort to make it explicit, does that mean that the research findings provide a valid ground for practical conclusions? This is often assumed to be the case, but repeated assumption does not make a belief valid. A sound theoretical and methodological grounding of research - at least in the usual understanding of 'theory' and 'methodology' - implies at best the empirical (i.e., descriptive) but not the normative (i.e., prescriptive) validity of the findings. Well-grounded research may tell us what we can and cannot do, but this is different from what we should do on normative grounds.

When it comes to this sort of issue, the researcher has no advantage over other people. Competence in research then gains another meaning, namely, that of the self-limitation of the researcher. No method, no skill, no kind of expertise answers all the questions that its application raises. One of the most important aspects of one's research competence is therefore to understand the questions that it does not answer. But the number of questions 
that you may ask is, of course, infinite. You have thus good reason to worry about the meaning of competence in research. If you want to become a competent researcher, you should indeed never stop worrying about the [\|7] limitations of your competence! As soon as you stop worrying, the deadly disease may strike. The goal of your quest for competence is not to be free of worries but rather to learn to make them a source of continuous learning and self-correction. That is the spirit of competent research.

Competence in research thus does not mean that research becomes a royal road to certainty. What we learn today may (and should) always make us understand that what we believed yesterday was an error. The more competent we become as researchers, the more we begin to understand that competence depends more on the questions we ask than on the answers we find. It is better to ask the right questions without having the answers than to have the answers without having asked, and continuing to ask, the right questions. If we have not asked the right questions we will not understand our answers properly; that is, they will not mean a lot.

This holds true as much in the world of practice as in research, of course. The difference may be that under the pressures of decision-making and action in the real world, the process of questioning is usually severely constrained. It usually stops as soon as answers are found that serve the given purpose. Limitations of time and resources are unavoidable, but as a competent practitioner you will want to handle these limitations differently. You will not want to limit your questioning before you understand the limited use to which the answers can be put. Whether as a researcher or a practitioner, you will therefore want to shift the main focus of self-limitation from the questions to the answers.

Your tentative first definition of competency in research, then, might be something like this: competence in research means pursuing a self-reflective, self-correcting, and selflimiting approach to inquiry. This means that I seek to question my inquiry in respect of all conceivable sources of possible deception; for example its (my) presuppositions, its (my) procedures, its (my) findings and the way I translate them into practical recommendations. The pronoun 'its' refers to the inherent limitations of whatever approach to inquiry I may choose in a specific situation, limitations that are inevitable even if I understand and apply that approach in the most competent way; the pronoun 'my', in contrast, refers to my personal limitations in understanding and applying the chosen approach.

A major implication of this preliminary definition is the following. Competence in research means more than mastering some research tools in the sense of knowing what methodology to choose for a certain research purpose and how to apply it in the specific situation of interest. Technical mastery, although necessary, is not equal to competence. It becomes competence only if it goes hand-in-hand with at least two additional requirements:

(1) that we learn to cultivate a continuous (self-)critical observation - in the double sense of 'understanding' and 'respecting' - of the built-in limitations of the chosen research approach, both in principle and in the specific situation of interest; and

(2) even more importantly and more radically, that we renounce the notion that we can ever justify the validity of our eventual findings by referring to the proper choice and application of methods. 
The obvious reason for (b) is that justifying findings by virtue of methods does little to justify the selectivity of those findings with respect to both their empirical content and their normative implications. Selectivity is the inescapable consequence of the limitations of any method (which is not to say that there are no other sources of selectivity). This is bad news, I fear, for some of you who base your search for competence on the idea of a theoreticallybased choice among methodologies. To be sure, there is nothing wrong with this idea - so long as you do not expect it to ensure critical inquiry. I know that this notion of securing critical systems inquiry through theoretically-based methodology choice is currently prominent in the domains of management science and systems research (for a representative collection of discussion papers, see Mingers and Gill, 1997); but I invite you to adopt it with caution. It does not carry far enough, for it remains captive to the assumption that we can justify the validity of research or [ $[\| \mathbf{8}]$ professional practice by referring to the proper choice and application of methods.

The question then is, 'What else can give us the necessary sense of orientation and competence in designing and critically assessing our research, if not (or not alone) the power of well-chosen methods?' I suggest that you consider first of all the following three additional sources of orientation that (among others) I have found valuable, namely:

- understanding my personal quest for 'improvement' in each specific inquiry;

- observing what (following Kant) I call 'the primacy of practice in research'; and

- recognizing and using the significance of C.S. Peirce's 'pragmatic maxim'.

The next three sections will explain these concepts. Further considerations will then concern the concepts of 'systematic boundary critique'; 'high-quality observations'; cogent reasoning and compelling argumentation; methodological pluralism; mediating between theory and practice (or science and politics); and finally, the 'critical turn' that is at the core of my work on Critical Systems Heuristics, that is, a critical heuristics of applied systemic thinking.

\section{THE QUEST FOR IMPROVEMENT}

One of the sources of orientation that I find most fundamental for myself is continuously to question my research with regard to its underlying concept of improvement. How can I develop a clear notion of what, in a certain situation, constitutes 'competent' research, without a clear idea of the difference it should make?

The 'difference it should make' is a pragmatic rather than merely a semantic category, that is, it refers to the implications of my research for some domain of practice. If I am pursuing a purely theoretical or methodological research purpose, or even meta-level research in the sense of 'research on research', the practice of research itself may be the domain in which I am interested primarily. But when we do 'applied' research in the sense of inquiry into some real-world issue, it will have implications for the world of social practice, that is,

2 I will discuss this issue a little further in the section on methodological pluralism later in this paper. 
the life-worlds of people and their interactions in the pursuit of individual or collective (organizational, political, altruistic, etc.) goals.

In either case I will need to gain a clear idea of the specific domain of practice that is to be improved, as well as of the kind of improvement that is required. One way to clarify this issue is by asking what group of people or organizations compose the intended 'client' or beneficiary of a research project, and what other people or organizations might be affected, whether in a desired or undesired way. (Note that from a critical point of view, we must not lightly rule out the possibility of undesired side-effects; when we seek to identify the people or organizations that might be affected, we should err on the side of caution and include all those whom we cannot safely assume not to be affected.) Together these groups of people or organizations constitute the domain of practice that I will consider as relevant for understanding the meaning of 'improvement'.

Once the client and the respective domain of practice are clear, the next question concerns the sort of practice that my research is supposed (or, critically speaking, likely) to promote. The competence of research expresses itself not by its sheer beauty but by its value to the practice it is to support. In order to have such value, it must be relevant - answer the right questions; and valid - give the right answers.

But how can we, as researchers, claim to 'know' (i.e., stipulate) the kind of practice to which we should contribute? Have we not been taught long enough that competent ('scientific') inquiry should refrain from being purpose- and value-driven? The German sociologist and philosopher of social science Max Weber (1991, p. 145) has given this concern its most famous formulation: 'Politics is out of place in the lecture room.' I can appreciate Weber's critical intent, namely, that academic teaching should be oriented towards theory rather than towards ideology. But can that mean, as Weber is frequently understood, that research is to be 'value-free'? A better conclusion, in my opinion, would be that as researchers we must make it [||9] clear to ourselves and to all those concerned, what values our research is to promote and whose values they are; for whether we want it or not, we will hardly ever be able to claim that our research serves all interests equally. We cannot gain clarity about the 'value' (validity and relevance) of our research unless we develop a clear notion of what kind of difference it is going to make and to whom. A clear sense of purpose is vital in competent research.

If you have experienced blockages in advancing your project, for example in defining research strategies and so on, ask yourself whether this might have to do with the lack of a sense of purpose. When you do not know what you want to achieve, it is very difficult indeed to develop ideas. Conversely, when your motivation and your vision of what you want to achieve are clear, ideas will not remain absent for long. Your personal vision of the difference that your research should make can drive the process of thinking about your research more effectively than any other kind of reflection.

\section{THE PRIMACY OF PRACTICE}

As a research student, your preoccupation with the question of 'how' to do proper research is sound. However, as we have just seen, the danger is that as long as you put this concern above all others, it will remain difficult to be clear about what it is that you want to achieve. 
For it means that you rely unquestioningly on a very questionable assumption, namely, that good practice $(\mathrm{P})$ - 'practice' in the philosophical sense of praxis rather than in the everyday sense of 'exercise' - is a function (f) of proper research (R), where 'proper' essentially refers to adequate research methodology, thus:

$$
\mathbf{P}=\mathbf{f}(\mathbf{R})
$$

Good practice often enough depends on proper research, but does this mean that the choice of research approaches and methods should determine what is good practice? I do not think so. Quite the contrary, it seems to me that good research should be a function of the practice we are aiming at:

$$
\mathbf{R}=\mathbf{f}(\mathbf{P})
$$

Your primary concern, then, should not be how to do proper research but what for.

This conjecture requires an immediate qualification, though, concerning the source of legitimation for the 'what for': Note that in our inverted formula, practice $(\mathrm{P})$ is no longer the dependent variable but is now the independent variable. It is not up to the researcher to determine what is the right or legitimate 'what for'; rather, it is the researcher's obligation to make it clear to himself or herself and to all those concerned, what might be the practical implications of this research, that is, what kind of practice the research is likely to promote the factual 'what for'.

After that, practice must itself be responsible for its purposes and measures of improvement. Researchers may be able to point out ways to 'improve' practice according to certain criteria, but they cannot assign to themselves the political act of legitimizing these criteria (cf. Ulrich, 1983, p. 308). It is an error to believe that good practice can be justified by reference to the research methods employed. Methods need to be justified by reference to their implications for practice, not the other way round!

In competent research, the choice of research methods and standards is secondary, that is, a function of the practice to be achieved. Good practice cannot be justified by referring to research competence. Hence, let your concern for good research follow your concern for understanding the meaning of good practice, not the other way round.

The suggested primacy of the concern for the outcome of a research project over the usually prevailing concern for research methodology (the 'input', as it were) is somewhat analogous to Kant's (1788, p. A215) postulate of the 'primacy of practice', by which he meant that practical (ethical) reasoning is more important than theoretical-instrumental reasoning; for practical reasoning leads us beyond the limitations of theoretical knowledge. I would therefore like to think of our conclusion in terms of a primacy of practice in research. [|[10]

This stipulation seems aptly to remind us that the concept of competent research that I suggest here is based on Kant's two-dimensional concept of reason. This distinguishes it from the concept of competent research that is implicit in much contemporary theory of knowledge and of science, which unfortunately has lost sight of the indispensable normative dimension of rationality. I am thinking of the model of empirical science that has come to dominate the actual practice of applied science: this model is rooted in the logical empiricism of the socalled Vienna Circle of the 1930s (Schlick, Carnap, Reichenbach, and others) and has since 
then been modified by the 'Critical Rationalism' of Karl R. Popper $(1959,1963,1972)$ and others (Albert, Spinner). There exist other important traditions of the theory of knowledge, such as those of Analytical Philosophy (e.g. Wittgenstein, Russell, Austin, Searle and others); Critical Theory (Horkheimer, Adorno, Habermas and others); and the 'Anarchistic' Theory of Knowledge (Feyerabend); but none has become as popular and has influenced the model of science in the minds of practical scientists as much as Popper's model.

It is Popper's historical merit that he has shifted the focus of science-theory from the unprofitable problem of inductive justification - a logical impossibility - to the need for sustaining intersubjective criticism of scientific statements with regard to their empirical validity. This is so because all such statements, and the observations on which they rest, are theory-loaded or 'theory-impregnated', in that they depend on our conscious or unconscious models of the world, our 'horizon of expectations' (Popper, 1972, p. 345). It follows that scientific statements are merely conjectural and remain provisional until they can be 'falsified' by observations that are informed by more accurate theories. Contrary to what had been assumed before Popper, the aim of science is not to verify its propositions but rather, to falsify them! The growth of knowledge depends on this never-ending process of eliminating falsified conjectures. This has a beautiful consequence for our concept of competent inquiry: it liberates the individual inquirer from the obligation of being error-free. The essential quality of a competent inquirer is not to be error-free but rather to make sure that his theories can be refuted by experience.

Unfortunately, however, Popper focuses so much on the theoretical and conjectural character of all statements, including those of applied science, that he loses sight of the fact that no statements of practical relevance are ever merely theory-loaded, but that they are always at the same time value-loaded - they depend on normative claims. Popper's procedure for testing the validity of theoretical hypotheses, the falsification principle, relies on deductive logic and observation: it aims to find observational statements that are inconsistent with the hypotheses in question. But observation and deductive logic are not sufficient tools for assessing the normative content of propositions; they offer no test for ethical issues. This explains why Popper replaces Kant's richer, ethical concept of the 'primacy of practice' by a 'primacy of theory' even in the context of applied science.

Since the normative dimension of reason finds no place in this model of practical rationality, Popper needs to refer it to an irrational realm of merely subjective acts of belief, the so-called 'psychological context'. The implication is scientism, a view that identifies the rational with the scientific. Scientism makes the rationality standards of empirical science the standards of rational practice, thereby reducing questions of practical reason to questions of theoretical reason (Ulrich, 1983, p. 24; for a detailed critique of Popper's Critical Rationalism, see pp. 26-30 and the entire Ch. 1, pp. 41-105).

To conclude this brief discussion of the suggested primacy of practice in research, let us consider an example of what it means in actual research practice. Research into poverty provides a good illustration with which I am familiar through my own engagement in this field (see, e.g., Ulrich, 1989, 1994b; Ulrich and Binder, 1992 and 1998; Ammann et al., 1993). Poverty researchers are often expected to tell politicians 'objectively' how much poverty there is in a certain population and what can be done about it. But poverty is a complex concept that stands not only for a precarious financial situation of people but also for their being deprived of chances of 'normal' participation in society. [||11] Hence, we cannot 
measure poverty without clear criteria of what standards of participation (both material and immaterial) we consider 'normal' (and therefore should seek to assure to all members of that population). If poverty research is to be done in a competent way, so that it can tell us who and how many of us are poor and what are their needs, there must first be a clear vision of the kind of just society to be achieved! Any scientific statement about poverty is thus not merely theory-loaded but is equally value-loaded, whence it is not sufficient for a competent poverty researcher to define poverty measures with reference to theoretical knowledge and to instrumental considerations concerning the feasibility of alternative measurements. Yet this is exactly what economists do when they define one of the most widely used measures of poverty in the purely statistical terms of a 'poverty line' defined by half the equivalent median income of households - equivalent, that is, to a standard one-person household. Apart from confusing poverty with low income, such a definition bypasses the crucial question of what kind of society we want to create; accordingly, poverty studies of this kind have in the past provided little impetus for social change.

The theoretical and the normative dimensions of reason are clearly inseparable in this example: we cannot know how much poverty there is empirically before we know what poverty means normatively, that is, who ought to count as poor. This is a question which the poverty researcher cannot assign to himself/herself but which only social practice can answer, through a discourse involving all those concerned and leading to a democratically legitimate process of decision-making. Social practice must itself attend to its purposes. This is what I mean by the primacy of practice in research.

\section{THE PRAGMATIC MAXIM}

The orientation provided by the notion of a primacy of practice must not be confused with mere 'pragmatism' in the everyday sense of orientation toward what 'works' or serves a given purpose. The essence of a well-understood pragmatism is not utilitarianism but the clarity of our thinking that we can obtain through clarity of purpose. This idea was first formulated by Charles S. Peirce (1878) in his pragmatic maxim, in a now famous paper with the significant title 'How to Make Our Ideas Clear':

Consider what effects, which might conceivably have practical bearings, we conceive the object of our conception to have. Then, our conception of these effects is the whole of our conception of the object. (Peirce, 1878, par. 402)

The pragmatic maxim thus requires from us a comprehensive effort to bring to the surface and question the implications, the actual or potential consequences that our research may have for the domain of practice under study. Contrary to popular pragmatism, according to which 'the true is what is useful', the pragmatic maxim for me represents a critical concept. The true is not just what is useful but what considers all practical implications of a proposition, whether it supports or runs counter to my purpose. Uncovering these implications becomes an important virtue of competent inquiry and design in general, and of critical systems thinking in particular.

The critical kernel of the pragmatic maxim as I understand it is this: Identifying the implications of a proposition is not a straightforward task of observation but raises difficult 
theoretical as well as normative issues. Theoretically speaking, the question is, what can be the empirical scope of our research? Normatively speaking, the question is, what should we consider to be relevant 'practical implications'? Peirce's solution is of course to consider all conceivable implications, but for practical research purposes that answer begs the question of how we can limit the inquiry to a manageable scope. The quest for comprehensiveness is reserved to heroes and gods; it is beyond the reach of ordinary researchers. What we ordinary researchers recognize as relevant implications depends on boundary judgements by which we consciously or unconsciously delimit the situation of concern, and thus on the reference system of our validity claims. [ [\|12]

This is the starting point of my thinking on Critical Systems Heuristics (the basic source is Ulrich, 1983; as introductory texts consult Ulrich, 1984, 1987, 1993, 1996a, 1998b, and 2000a). Critical Systems Heuristics interprets and operationalizes the pragmatic maxim in a new way by linking it, on the one hand, to the tradition of systems thinking, and on the other hand to the tradition of critical social theory. Both traditions we can trace back, largely and importantly, to the work of Charles Peirce. Critical Heuristics is thus not merely the work of a lone author who has drawn on the work of Peirce; rather, it is part of a stream of literature critical systems thinking - that seeks to build a bridge between two seemingly incompatible paradigms of contemporary thought, the systems-theoretic and the discourse-theoretic concepts of rationality. Neither of the two paradigms has thus far produced a model of rationality that would be both practicable and critically tenable at the same time. While the tradition of systems theory has long been rather weak with respect to the philosophical foundation and critique of applied systems thinking, the tradition of critical social theory has been similarly weak with respect to the practicability of its critical ideas. If we are to learn how we can practise the pragmatic maxim in a critical way, we need a way out of this impossible alternative of practicability versus critical defensibility. The way out that I propose with Critical Heuristics is what I call a process of systematic boundary critique. Before I introduce this core idea of my approach in the next section, however, I need to situate it in the two traditions of which it is a part, for the mentioned reason.

To begin with the systems-theoretic tradition, I owe my interest in systems thinking to my philosophy teacher (in the 1970s) at the University of California at Berkeley, C. West Churchman (see Ulrich, 1999). Churchman had helped to pioneer the applied mathematical fields of Operations Research and Management Science in the 1950s and then, since the 1960s, has become a pioneer and leading philosopher of the systems approach to problem solving and decision-making. The systems approach for me represents the methodological development of systems theory from 'hard' (objectivist) to 'soft' (interpretive) systems thinking. ${ }^{3}$ Churchman's philosophical teacher at the University of Pennsylvania in Philadel-

'Soft' or interpretive systems theory distinguishes itself from conventional 'hard' systems theory (which includes first-generation cybernetics and much of contemporary systems science) in that it does not assume the 'systems' it studies to be given objectively in the real-world but rather takes them to represent conceptual tools or distinctions by which we construe a complex reality so as to render it intelligible and accessible to systematic study. Within the tradition of systems theory Churchman's work, although originally rooted in the 'hard' systems theory of his time (Bertalanffy, Wiener, Ashby, Rapoport, Forrester, and others), represents an early major contribution to the development of soft systems thinking, to which more recently Ackoff (1974, 1981; Ackoff and Emery, 1972), Checkland (1981, 1985) and Luhmann (1984, 1997) have made particularly outstanding contributions. 
phia was Edgar A. Singer, Jr., who in turn was a disciple of William James, the second great American pragmatist after Charles Peirce.

Singer's philosophical stance made him seek ways to overcome the prevailing logical empiricism of his day. One of his key ideas was the 'sweep-in' process, a systematic attempt to consider ever more aspects of a problem situation so as to live up to the pragmatic maxim. With his systems approach, Churchman (e.g., 1968a, b, 1970, 1971, 1979, 1982a, b) conceived of this process in terms of the (re-) design of social systems. Singer's 'sweep-in' process thus became a systematic process of expanding the boundaries of the system of interest, which meant that the system had to be to examined and redesigned in the light of the 'larger system' (in conventional systems theory, the level of the super system). But of course, there is no definitive way to bound the larger system. The system designer's quest for comprehensiveness is endless; even his or her most heroic "whole systems judgements" can always be questioned. The question remains: [\|13]

How can we design improvement in large systems without understanding the whole system, and if the answer is that we cannot, how is it possible to understand the whole system? (Churchman, 1968a, p. 3)

This question led Churchman to conceive of his systems approach as an endless, dialectical process of maintaining the contradiction: the system designer should never stop sweeping in new aspects of the 'whole system', including perspectives that may contest the rationality of the systems approach on grounds of principle, for example from a religious, moral, political, or aesthetic perspective. Hegelian dialectical reasoning should drive this process of expanding the considered system. In The Systems Approach and Its Enemies, Churchman (1979) has given this dialectical systems approach its most elaborate expression. We can thus characterize his pragmatism as a systems-theoretically-informed dialectical pragmatism.

Critical Systems Heuristics may be seen as an effort to continue this tradition of thought in the light of and with the help of contemporary philosophical conceptions, in particular the language-pragmatic (also called communication-theoretic or discourse-theoretic) turn of practical philosophy $^{6}$ as represented by the seminal works of Karl-Otto Apel (e.g., 1972,

4 Churchman has explained and appreciated the importance of Singer's work in several of his books (e.g., Churchman 1971 and 1979; see also Singer, 1959) as well as in a personal appreciation (1982a). I have similarly tried to acknowledge the influence that Churchman's work had on me in Critical Heuristics (Ulrich, 1983) and in a series of tribute articles (1980, 1981, 1985, 1988b, c, 1994a, 1999).

5 Churchman's term for the boundary judgements by which we delimit the problem we consider. In Critical Heuristics I prefer the neutral term 'boundary judgements', to avoid any possible holistic associations. I do not want to assume that when it comes to bounding the relevant system of concern, bigger is always better. The difference in terminology may seem small, but it captures the move from Singer's and Churchman's holistic understanding of the systems approach as a quest for comprehensiveness, toward Critical Heuristics' understanding of the systems approach as a form of critical reasoning only - the story I am about to tell. From a strictly critical point of view, what matters is not so much expanding systems boundaries but breaking through the illusion of objectivity that frequently surrounds them. 'Not what our boundary judgements are but how we treat them will determine the quality of our systems thinking in the first place.' (Ulrich, 1988c, p. 420) In fact, I would say that since attaining comprehensiveness is impossible, the sweep-in principle begs the problem of boundary judgements!

6 I will explain the two concepts of practical philosophy and its language-pragmatic turn further on. I have explained the meaning and importance of this turn of contemporary practical philosophy elsewehere; see Ulrich, 1988a. 
1976a, b) and Jurgen Habermas (1970, 1973, 1979, 1984-87). Not by chance are these two authors also responsible, to a large extent, for the recent renaissance of American pragmatism in European philosophy; both have published influential new interpretations of the work of Peirce in the light of the language-pragmatic turn (see Apel, 1967-70, and Habermas, 1971a) and are thus also rooted in the tradition of Peirce, although in quite different ways from Singer and Churchman. Habermas is, of course, most famous for his work on critical social theory, especially the Theory of Communicative Action (1984-87), with which he continued and transformed the 'Critical Theory' of the so-called Frankfurt School of Horkheimer, Adorno, Benjamin, Marcuse, Fromm, and others. His work represents the second major tradition of thought that has influenced Critical Heuristics ${ }^{7}$ and which at the same time has been strongly influenced by (among other sources) the pragmatic philosophy of Peirce.

Of Habermas' immense work, the aspect that has mattered most to Critical Heuristics has been the language-pragmatic turn of practical philosophy that he pioneered along with Apel. Practical philosophy is the branch of philosophy that deals with the requirements of rational practice. Its core problem asks how we can justify the normative content of our actions, that is, the normative claims that we raise, whether consciously or not, when we act or when we propose an action or the 'right' definition of a problem: what entitles us to claim a 'good' solution or an 'appropriate' evaluation of a situation, or a 'moral' principle of action, a real 'improvement', and so on? To the extent that we can defend such claims 'with reason', that is, by arguments that those concerned accept of their own free will, we rely on practical reason rather than on power or other non-argumentative means. Such an ideal of rational practice may look rationalistic at first; but unless we want to live under the rule of brachial force, there is no alternative to trying to regulate our human affairs and conflicts with reason. Practical philosophy, then, is the philosophical effort to come to terms with this fundamental problem of practical reason: How can we rationally identify and justify the normative content of our actions, and of all claims to practical knowledge or rationality in general? This is a central concern of Habermas' work.

Traditional practical philosophy analysed this question from the perspective of an individual agent's consciousness (philosophy of consciousness). The language-pragmatic turn of contemporary practical philosophy replaces this traditional starting point by an intersubjective process of argumentation mediated through language and discourse (philosophy of language, [||14] discourse theory). Practical reason is now seen as the (ideal) outcome of discourse rather than of individual reflection and conscience; Kant's $(1786,1788)$ categorical imperative may be regarded as the ultimate expression of the 'old' approach and Habermas' model of practical discourse as its 'modern' counterpart. This model plays a central methodological part in Habermas' approach, for it takes the place that the categorical imperative played in Kant's 'monological' (rather than dialogical or discursive) approach: it provides the 'test' for deciding whether the outcome of a discourse - ideally a consensus meets the requirements of practical reason. When it came to an evaluation, the question for Critical Heuristics was, can Habermas' theoretical model fulfil this role in practice, that is, is it operational and non-elitist?

I was fortunate enough to meet Jurgen Habermas and also to be able to attend some of his classes during my last year of working with West Churchman at the University of California, Berkeley, when Habermas was a Visiting Professor in the Departments of Political Science and of Sociology there (in 1980). 
My answer, after an intensive study of Habermas' approach that is documented in the second chapter of Critical Heuristics (Ulrich, 1983, pp. 106-172), was negative, for various reasons. I can only mention a few here. First, Habermas' model makes rationally argued consensus the criterion of practical reason. In real-world decision-making, however, consensus is a scarce resource. In a world characterized by an increasing pluralism of values and interests, a concept of rational practice that depends on consensus risks begging the real issue, of how we can deal with genuine conflicts of interest in a reasonable and democratic way without resorting to non-argumentative means such as power, coercion, manipulation, deception, dogmatism, and so on. Second, Habermas' model serves the theoretical purpose of discovering the sufficient conditions that would allow us to call a factual consensus 'rational'. This is the famous 'ideal speech situation' (Habermas, 1970, 1973, 1979). Such a model, as useful as it is for understanding the implications of any claim to rationality, cannot make the ideal speech situation real; taken for a practical model of discourse, the model must presuppose what it is supposed to produce, namely, rational argumentation on the part of everyone involved. Third, as a last point, Habermas' model and the huge body of literature that surrounds it do not at all consider the systems-theoretic insight into the inevitability of boundary judgements. In practice, any discourse must start with some premises and end with some implications that it cannot question and justify any further; these unexamined premises and implications embody the boundary judgements that conceptually separate the considered system of concern from its environment. Practical claims to rationality are not critically tenable unless they make explicit the inevitable boundary judgements on which they rely, and examine their implications in the light of alternative reference systems.

These remarks must suffice to embed my approach to philosophical pragmatism within the two traditions that have influenced it most. (A third major source is a reconstruction of Kant's [1787] critique in the light of the two traditions rooted in Peirce; see Chapters 3-5 of Critical Heuristics). My remarks do not try to do justice to the works of Churchman and Habermas; that is beyond the scope of this brief discussion. If I have emphasised more the limitations than the considerable merits of both authors (merits which I have appreciated elsewhere in detail; see Ulrich, esp. 1983, 1988a and 1999), it is because my only purpose here is to help the reader understand the rationale of my suggested critical understanding and operationalization of the pragmatic maxim.

\section{SYSTEMATIC BOUNDARY CRITIQUE}

We have already understood that boundary judgements are inevitable. They are the result of our inability to consider 'the whole system' of all the conditions that (in the terms of the pragmatic maxim of Charles S. Peirce) 'might conceivably have practical bearings' on the way we see an issue of concern. Since nobody can ever claim comprehensiveness for his or her consideration of possibly relevant 'facts' (empirical observations or anticipations) and 'values' or 'norms' (normative assumptions or implications), what matters from a critical

8 For a summary appreciation and a critical comparison of the basic aims and assumptions of Habermas' programme of a critical theory of society as distinguished from the idea of a critical heuristics of social planning, see the chapter's final section, entitled 'Conclusions: Critical Theory or Critical Heuristics?' (Ulrich, 1983, pp. 152-172). 
point of view is not so much how [\|15] comprehensive our boundary judgements are, but rather how carefully we deal with their inevitable lack of comprehensiveness. Dealing critically with boundary judgements is therefore a key concern of critical systems thinking as I understand it (see Ulrich, 1983, pp. 225-314; 1987; 1988c, pp. 420-427; 1993, pp. 594605; 1996a, pp. 15-44; and 1998b, pp. 5-12; see also Midgley, 1992a, 1994, 1996a; Midgley et al. 1998.) An adequate approach to critical systems thinking should provide both a philosophical foundation and a practical operationalization of the critical employment of boundary judgements. Critical Systems Heuristics tries to accomplish precisely this.

Critical Heuristic's response to Peirce's challenge is thus that we must make it clear to ourselves and to all others concerned, in what way we (or they) may fail to be comprehensive, by undertaking a systematic effort to identify and challenge the boundary judgements at work. This is what the process of systematic boundary critique is all about. ${ }^{9}$ In order to facilitate this process, Critical Heuristics offers a conceptual framework that includes, among other tools, twelve basic boundary concepts and a checklist of corresponding boundary questions. I have explained these tools on earlier occasions and therefore need not introduce them again; see Ulrich (1983, pp. 240-264; 1987, p. 279f; 1993, pp. 594-599; 1996a, pp. 19-31 and 43f; 2000a).

For me this critical effort of disclosing and questioning boundary judgements serves a purpose that is relevant both ethically and theoretically. It is relevant theoretically because it compels us to consider new 'facts' that we might not consider otherwise; it is relevant ethically because these new facts are likely to affect not only our previous notion of what is empirically true but also our view of what is morally legitimate, that is, our 'values' or 'norms'.

What I propose to you here is not as yet a widely shared concept of competence in research, but I find it a powerful concept indeed. Once we have recognized the critical significance of the concept of boundary judgements, we cannot go back to our earlier 'precritical' concept of competent research, for example in terms of empirical science. It becomes quite impossible to cling to a notion of competent research that works in only one dimension. This is so because what we recognize as 'facts' and what we recognize as 'values' become interdependent.

The question of what counts as knowledge, then, is no longer a question of the quality of empirical observations and underpinning theoretical assumptions only; it is now also a question of the 'proper' bounding of the domain of observation and thus of the underpinning value judgements as to what ought to be considered the 'relevant' situation of concern. What counts as knowledge is always at the same time a question of what ought to count as knowledge. We can no longer ignore the practical-normative dimension of research or relegate it to a non-rational status.

9 I have used this term since 1995 (cf. Ulrich, 1995, pp. 13, 16-18, 21; 1996a, pp. 46, 50, 52; 1996b, pp. 171, 173, 175f; 1997, p. 31; 1998a, p. 7; 1998b, p. 7; 2000a). Previously I was usually speaking of a 'critical employment of boundary judgements', but the methodological idea was the same, namely, to promote a discursive process of appreciating and reviewing boundary judgements so that their selectivity and changeability might become visible. In the meantime, G. Midgley et al. (1998) have also adopted the new term to designate their similar concerns. 


\section{WHAT OUGHT TO COUNT AS KNOWLEDGE?}

Research is usually undertaken to increase knowledge. A typical dictionary definition explains that research is 'to establish facts and reach new conclusions' (The Concise Oxford Dictionary of Current English). This is not a bad definition. Counter to the frequent identification of research with empirical research, the Oxford definition tells us that research requires two kinds of competencies:

- observational skills to 'establish facts', and

- $\quad$ argumentative skills to 'reach new conclusions'.

The first kind of skills refers to the ideal of high-quality observations, that is, observations that are capable of generating valid statements of fact. This ideal is traditionally but inadequately designated 'objectivity'; it requires our statements to possess observational qualities such as intersubjective transferability and controlability, repeatability over time, adequate precision, and clarity [\|16] with respect to both the object and the method of observation.

The second kind of skills refers to the ideal of cogent reasoning, that is, processes of (individual) reflection and (intersubjective) argumentation that generate valid statements about the meaning (interpretation, justification, relevance) of observations. This ideal is traditionally designated 'rationality'; it requires our statements to possess communicative and argumentative qualities such as syntactic coherence, semantic comprehensibility, logical consistency with other statements, empirical content (truth), pragmatic relevance and normative legitimacy (rightness).

Both kinds of skills raise important issues for the concept of research competence. How can we know whether we 'really' know, that is, judge whether our observations are highquality observations or not? And if we can assume that they are, how can we know whether we understand their meaning correctly and draw the 'right' conclusions?

A particular difficulty with the two requirements is that they are inseparable. This becomes obvious as soon as we consider the nature of the 'facts' that quality observations are supposed to establish:

Facts are what statements (when true) state; they are not what statements are about [i.e., objects]. They are not, like things or happenings on the face of the globe, witnessed or heard or seen, broken or overturned, interrupted or prolonged, kicked, destroyed, mended or noisy. (Strawson, 1964, p. 38; cf. Ulrich, 1983, p. 132)

That is to say, 'facts' are not to be confused with objects of experience; they cannot be experienced (they are statements rather than objects), just as objects of experience cannot be asserted (only statements can). Facts, because they are statements, need to be argued. Both observational and argumentative competencies must thus go hand-in-hand in competent research; they are but two sides of one and the same coin (Figure 1). 


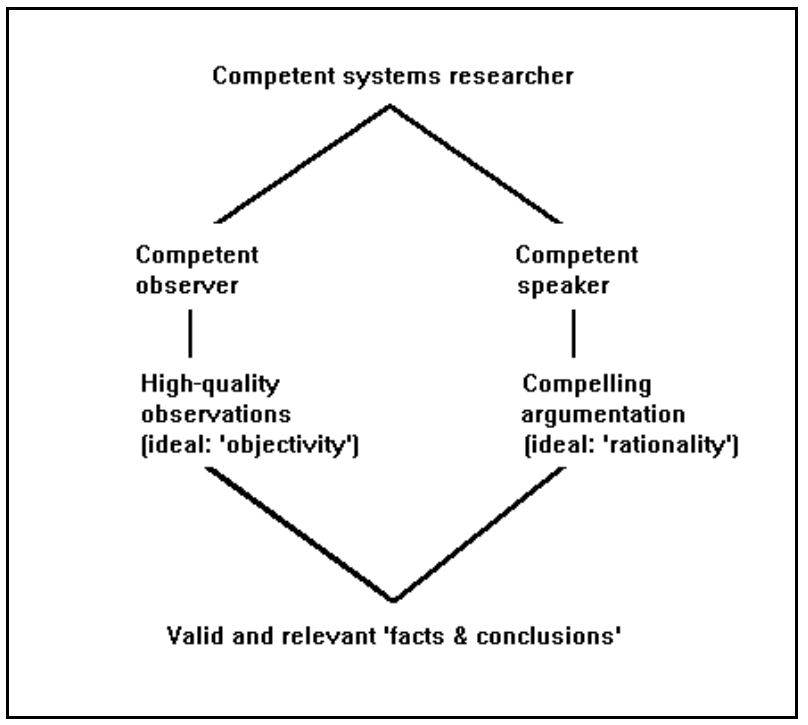

Figure 1. Two dimensions of competence required in research: observational and argumentative competence. Each dimension entails specific validity claims, the redemption of which may, however, involve claims that refer to the other dimension.

Let us consider some of the specific requirements on each side of the coin. On the argumentative side, Habermas' (1979, pp. 2f and 63f) well-known model of rational discourse gives us a framework for analysing the difficult implications of the quest for communicative competence. According to this model, a competent speaker would have to be able to justify (or 'redeem', as Habermas likes to say) the following validity claims that all rationally motivated communication entails:

(1) Comprehensibility: a claim that entails the obligation to express oneself in a way that the listeners can hear and understand; it cannot be redeemed discursively but merely through one's communicative behaviour.

(2) Truth: a claim that entails the obligation to provide grounds for the empirical content of statements, through reference to quality observations and through theoretical discourse.

(3) Rightness: a claim that entails the obligation to provide justification for the normative content of statements, through reference to shared values (e.g., moral principles) and through practical discourse.

(4) Truthfulness: a claim that entails the obligation to redeem the expressive content of statements by proving oneself trustworthy, so that the listeners can believe in the [\|17] sincerity of the speaker's expressed intentions; again, this cannot be redeemed discursively but only through the consistency of the speaker's behaviour with the expressed intentions.

Since these validity claims are always raised simultaneously in all communication, whether explicitly or implicitly, it becomes apparent that a competent researcher must be prepared to substantiate statements of fact not only through credible reference to quality observations but 
also through theoretical and practical discourse, so as to convince those who contest the 'facts' in question, of the validity of their theoretical and normative presuppositions.

Similar difficulties arise with the requirement of substantiating the 'high quality' of observations. Observations always depend on the construction of some sorts of objects that can be observed and reported upon. Depending on the situation, these constructions may need to rely on different notions of what kinds of 'objects' lend themselves to quality observations. A conventional notion of objects assumes that the objects of observation can be construed to be largely independent of the purposes of both the observer and the user of the generated knowledge. In such a conventional account, a claim to present quality observations will entail the obligation to redeem at least the following requirements:

(1) Validity: the observation observes (or measures) what it is supposed to observe (or measure).

(2) Reliability: the observation can be repeated over time and provides (at least statistically) a stable result.

(3) Transferability: the observation can be repeated by other observers and in that sense proves to be observer-independent (a validity claim that is often subsumed under 2).

(4) Relevance: the observation provides (together with other observations) information that serves as support for a statement of fact or for an argument for the truth of some disputed 'fact'.

Historically speaking, these or similar assumptions characterized the rise of the empirical sciences (especially the natural sciences) about three centuries ago. More recently, however, with the extension of scientifically motivated forms of inquiry to ever more areas of human concern, competent research faces increasingly the difficulty that, contrary to the original assumptions, quality observations cannot be assumed to be independent of either the observer or the user or both. As for instance G. de Zeeuw (1996, p. 3 and p. 19f) observes, science is now more and more faced with the challenge of the user, that is, the task of constructing quality observations that allow users to have a voice inside science. This is different from conventional science which, because of its underlying notion of non-constructed, observerand user-independent objects, depends on the exclusion of users.

Typical examples are research efforts in the domain of therapy (e.g. psychiatry), social intervention (e.g., care for the elderly or fighting poverty), and organizational design (e.g., management consultancy). 'Patients', 'clients' and 'decision-makers' increasingly claim a voice in the making of the observations of concern to them; they do not want 'diagnoses', 'help' or 'solutions' to be simply imposed upon them without their views being considered. What does it mean for a researcher to assure high-quality observations in such circumstances?

De Zeeuw has discussed this issue extensively (e.g. 1992, 1995, and particularly 1996). He distinguishes three notions of 'objects' that allow quality observations in different circumstances (the examples are mine): 'non-constructed objects' (e.g. the seemingly given, observer-independent objects of astronomy such as the celestial bodies and phenomena),

10 Strictly speaking, observer-independence does not imply that objects are 'non-constructed'; it only implies transferability in the sense of the above-mentioned requirement of conventional 'high-quality observations'. I understand de Zeeuw's language as referring to ideal types of 'objects' only, ideal types that may help us 
'constructed objects' (e.g. [\|18] groups such as 'the poor' or 'the upper class' as objects of the social sciences, or 'systems' as objects of the systems sciences), and 'self-constructed objects' (e.g. expressions of human intentionality as objects of study in social systems design, organizational analysis, environmental and social impact assessment, action research etc., where the construction of the objects to be observed is left to those who are concerned in the observations at issue, either because they may be affected by them or because they may need them for learning how to achieve some purpose, or else because they may be able to contribute some specific points of view). The three notions of objects give rise to three developments of science which de Zeeuw calls 'first phase', 'second phase' and 'third phase' science.

If I understand de Zeeuw correctly, the constructed objects of second-phase science distinguish themselves from the non-constructed objects of first-phase science in that they depend on the observer's purpose (e.g., the improvement of some action or domain of practice). The self-constructed objects of third-phase science depend, moreover, on the full participation of all the users of the knowledge that is to be gained.

The notion of competent systems research that I pursue in this essay and which is also contained in my work on Critical Heuristics is certainly sympathetic to the idea of combining 'the challenge of the user' with an adequate notion of (objects of) high-quality observations, a notion of quality that - in my terms - would give a competent role to all those concerned in, or affected by, an inquiry. I thus agree with de Zeeuw (1996, p. 19) when he refers to Critical Systems Heuristics as an effort to concentrate on 'the need to give users in general a voice inside science', so as to overcome the conventional limitation of quality observations to objects that are constructed by researchers without the full participation of users. It should be noted clearly, however, that Critical Heuristics aims beyond the instrumental purpose of improving the quality of 'scientific' observations; it also aims at emancipating ordinary people from the situation of incompetence and dependency in which researchers and experts frequently put them in the name of science. It aims at the earlier-mentioned insight that what in our society counts as knowledge is always a question of what ought to count as knowledge, whence the issues of democratic participation and debate and of the role of citizenship in knowledge production become essential topics. That is why I find it important to associate the 'challenge of the user' with the goal of allowing citizens to acquire a new competence in citizenship (Ulrich, 1995, 1996a, b, 1998a, b, 2000a).

One fundamental source of such competence I believe to have found in the unavoidable boundary judgements that underpin all application of research and expertise to real-world issues but in respect of which researchers or experts enjoy no advantage over ordinary citizens (compare the earlier section on 'Systematic Boundary Critique'). Once we acknowledge the unavoidability and meaning of boundary judgements, not only will our concept

understand the historical and present development of science but do not necessarily exist as such in the actual practice of science. Nor would I equate them with philosopically unproblematic notions of scientific objects. The notion of 'non-constructed objects' in particular appears to be tenable only within a philosophically uncritical realism or empiricism. On more critical grounds, it would appear that all objects are constructed; even the celestial bodies of astronomy are constructed as 'stars', 'moons', 'constellations', 'comets', etc., before they are conceptually subsumed under one or several classes of celestial objects. Taking the example of 'comets', they were not always construed as celestial bodies but earlier were seen as phenomena of the atmosphere. 
of high-quality observation change, but so equally will our concept of compelling argumenttation.

But of course, giving users a more competent voice within research does not answer all the questions raised by the search for valid and relevant 'facts and conclusions'. The deeper reason for this is that we are dealing with an ideal. A competent researcher will always endeavour to make progress toward it, while never assuming that he or she has attained it.

Given the ideal character of the quest for validation, we should not expect philosophers of science, either, to come up with safe epistemological guidelines. As far as the problem of ensuring high-quality observations is concerned, the basis for such guidelines would have to be some sort of practicable correspondence theory of truth. Such a theory would have to explain how we could establish a 'true' relationship (a stable kind of 'correspondence') between statements of fact and 'reality'. But since the latter is not accessible except through the statements of observers who, apart from being human and thus imperfect observers, construct 'reality' dependent on their particular viewpoints and purposes, it is clear that such a theory is not available on principle.

Similarly, with regard to the problem of securing compelling argumentation, the necessary [\|19] basis would consist in a practicable theory of 'rationally' argued consensus. A theory of rational discourse may be able to demonstrate the conditions for a rationally defendable (rather than merely factual) consensus; but, as we have learned from Habermas' analysis of the 'ideal speech situation', it will not enable us to make these ideal conditions real.

Insofar as the methods of natural science appear to provide a proven tool for ensuring scientific progress, many natural scientists may disregard this lack of philosophical grounding without worrying too much. The social sciences and the applied disciplines are in a less comfortable position, however. The way they deal with these issues is bound to affect the facts and conclusions that they will be able to establish. As applied researchers we should therefore deal especially carefully with the epistemological requirements of competence. But how can we square the circle and become epistemologically competent without sufficient epistemological guidelines?

\section{METHODOLOGICAL PLURALISM}

The unavailability of a satisfactory answer is probably responsible for the current rise of pluralism (also referred to as 'complementarism') in epistemological and methodological issues. In the systems and management sciences, the rise of pluralism has been heralded particularly in the writings of M.C. Jackson (e.g. 1987, 1990, 1991, 1997, 1999; see also Jackson and Keys, 1984, and Flood and Jackson, 1991) and, closer to my understanding of critical research and practice, by G. Midgley (e.g. 1992b, 1996a, b, 1997; Midgley et al., 1998) and J. Mingers (1997; Mingers and Brocklesby, 1996; Mingers and Gill, 1997). In different ways, it also underlies the work of other authors in the field (e.g. Linstone, 1984 and 1989; Oliga, 1988; Ormerod, 1997; White and Taket, 1997).

Unfortunately, the discussion around this issue has suffered from a number of confusions that have blurred the meaning of competent research and practice. It should have become 
clear in the present essay that critical practice cannot be secured by the kind of 'pluralistic' framework of methodology choice proposed by Flood and Jackson with their much-debated 'system of systems methodologies', for two main reasons. First, we have seen that we cannot justify the validity of research or professional practice by referring to the proper choice and application of methods, for this does nothing to justify the normative content of our claims (see the earlier discussions of the 'death of the expert' and of the 'primacy of practice'). Second, a well-understood epistemological and methodological pluralism goes far beyond the issue of methodology choice; in particular, it concerns the ways we deal with (a) the earliermentioned two-dimensionality of reason and (b) the requirement of systematic boundary critique.

Regarding (a), Critical Heuristics proposed and practised a deep complementarism of the theoretical-instrumental and the practical-normative dimensions of reason long before the current debate. Flood and Jackson's notion of methodology choice falls behind Critical Heuristics' treatment of the empirical and the normative as inseparable constituents of practical reason, for it amounts to a practice of methodology choice that treats the two dimensions as if they were methodologically separable. I have explained my notion of a fundamental complementarism in more detail elsewhere (see Ulrich, 1983, pp. 25, 131-136, 222, 277f and passim; 1988a, pp. 143-148 and 156f; 1993, p. 590; and especially 2000b).

Regarding (b), Critical Heuristics differs from the prevailing concept of methodology choice in the way it relates this to boundary critique. Depending on how we see this relationship, there are two views of methodological pluralism. The one (held by Flood and Jackson, see especially Jackson, 1999) subordinates boundary critique to the choice of a methodology that is deemed appropriate to the problem situation at hand. The other (held by myself, see especially Ulrich, 2000b, and by Midgley, see especially 1997) prioritizes it. In the first view, systematic boundary critique is reserved to situations that are assessed as being characterized by 'coercion' (influence of power), whereas in all other cases there are no provisions that would ensure a systematic review of boundary judgements. [\|20] In the second view, systematic boundary critique is an intrinsic part of any methodology and indeed of the assessment of the problem situation before any methodology choice. The first concept of pluralism is unacceptable to Midgley and me, for it treats boundary critique as a matter of choice (as a wrong alternative to instrumental and/or interpretive systems thinking) rather than as an indispensable part of all claims to knowledge or rationality. It offers no methodological safeguards against a naively instrumental use of systems methodologies that remains blind to its own normative implications and to the possible use of power or other nonargumentative means of supporting its claims to rationality. This kind of methodological pluralism is bound to lose sight of its own original purpose and claim, namely, of ensuring critical systems thinking and practice.

In conclusion, the opposition of methodology choice and boundary critique is not a critically tenable concept. From a critical point of view, we should never assume a problem situation a priori to be noncoercive and thus (allegedly) not to require a systematic process of boundary critique. Quite the contrary, a well-understood methodological pluralism should support the process of boundary critique by using a variety of methods to this end and in this spirit, rather than using 'pluralism' as an excuse for renouncing this critical effort.

As a last remark, let us not make a virtue of necessity. The call for epistemological and methodological pluralism may be justified by the lack of a sufficient, operational theory of 
knowledge and of rationality, but it cannot replace guidelines for a reflective practice of whatever methods we use, much less the critical spirit that moves us as researchers. Remember, it is an error to think that we can justify our propositions by referring to the methods we use, however well-informed and well-reasoned the choice of those methods may have been. Let us rather look for additional guidelines for reflective practice. Two sources of guidelines have become particularly important for my understanding of competence in research:

(1) Instead of seeking a basis for claims to knowledge and rationality in the scientific qualities of research alone, we might be better advised to seek to base them on a proper integration of research and practice. The issue that arises here is the model of the relationship of 'theory' and 'practice', or 'science' and 'politics', that should underpin our understanding of competence in (applied) research.

(2) Instead of seeking to validate claims to knowledge and rationality positively, in the sense of ultimately sufficient justification, we might be better advised to defend them critically only, that is, by renouncing the quest for sufficient justification in favour of the more realistic quest for a sufficient critique (laying open of justification deficits). The issue then is what I have called 'the critical turn'.

\section{MEDIATING BETWEEN THEORY AND PRACTICE}

Ever since the rise of science, there has been a hope that political practice, that is, the use of power, could be enlightened by science. At the bottom of this issue lies the question of the proper relationship between science and society, between technically exploitable knowledge and normative-practical understanding (and improvement) of the social life-world, between 'theory' and 'practice'.

Until the rise of science, Aristotle's view of practice (praxis) as a non-scientific domain of ethics and politics was generally accepted. It meant that practice could not be rationalized by means of theoretical knowledge (theoria) or technical skill (poiesis). In the middle of the seventeenth century, however, the English political philosopher Thomas Hobbes (1588-1679) proposed a first design for the scientization of politics. His insight was that practical issues raise questions that are accessible to science, namely, insofar as they require theoretical or technical knowledge. Once these questions have been identified, the remaining questions will then [\|21] properly remain inaccessible to science, for they require genuinely normative, subjective decisions that lie beyond rationalization through theory or technique. Thus decisionism was born, the doctrine that practical questions allow of scientific rationalization as far as they involve the choice of means; for the rest, they can only be settled through the (legitimate) use of power. Auctoritas, non veritas, facet legem, became Hobbes' motto: 'Power rather than truth makes the law'. The limited function of science, then, consists in informing those in a situation of (legitimate) power about the proper choice of means for their ends, according to the guideline: 'Knowledge serves power.'

11 The following account is based on my earlier discussion of 'The Rise of Decisionism' in Ulrich, 1983, pp. 67-79. Compare Habermas, 1971b, pp. 62-80. 
For the Enlightenment thinkers, this could not be the last word on the matter. Veritas, non auctoritas, facet legem, that is, 'Truth rather than power makes the law', was postulated by the French Enlightenment philosopher Jean-Jacques Rousseau (1712-1778) as a counterpoint to Hobbes. It was to take nearly two centuries for Rousseau's postulate to acquire some empirical content (descriptive validity) in addition to its normative content. The growth of administrative and scientific tools for rationalizing decisions, exemplified by the development of computers, decision theory and systems analysis in the middle of the twentieth century, led to a partial reversal of the relationship between the politician and the expert or researcher: the researcher's understanding of real-world issues increasingly tends to determine the need and criteria for political action. Indeed, one need only think of environmental issues to realize how much science nowadays defines the factual constraints to which politicians must succumb.

What remains to politics, then, is paradoxically the choice of the means that are capable of responding to the needs that have been defined by the experts. As a former chief evaluator in public administration, I have often experienced this peculiar reversal of roles: I was expected to come up with 'scientific' findings ('facts and conclusions') as to what needed to be done, so that the politician could then justify his chosen measures (or his inactivity) by referring to the recommendations of the evaluator. The danger is that the genuine function of politics, to ensure legitimate decisions on issues of collective concern, is in effect delegated to researchers who, because they hold no political mandate, are not democratically accountable.

To the extent that this reversal of roles takes place, the decisionistic model of the mediation between science and politics becomes technocratic. In the technocratic model, political debates and votes are ultimately replaced by the logic of facts; politics fulfils a mere stop-gap function on the way towards an ever-increasing rationalization of power (Habermas, 1971a, p. 64). Knowledge no longer serves power, as in the decisionistic model; knowledge now is power.

Max Weber (1991) foresaw this tendency. As a bulwark against technocracy, he sought to strengthen the decisionistic model by reformulating it more rigorously. He tried to achieve this by conceiving of an 'interpretive social science' that could explain (and thus rationalize) the subjective meaning of individual actions or decisions in terms of underlying motivations. Rather like Hobbes, he found that actions or decisions admit of scientific explanation insofar as they can be shown to represent a 'purpose-rational' pursuit of motivations. At the bottom of this concept is Weber's means-end dichotomy. It says that decisions on ends and the choice of means can be separated, in that the latter do not require value judgements of their own and hence are accessible to scientific support. This concept of purposive-rationality thus permits a rational choice of (effective and efficient) means at the price of renouncing any attempt to ensure the rationality of the purposes they serve.

Quite in the tradition of Hobbes, Weber thus relegated the choice of ends to a domain of genuinely irrational - because subjective and value-loaded - political and ethical decisions. Weber was willing to pay this price, since he hoped to achieve a critical purpose: lest it become technocratic, science should not misunderstand itself as a source of legitimation for value judgements on ends.

The problem with this self-restriction of science is not only that the question of proper ends remains unanswered - the effectiveness and efficiency of means, when used for the 
wrong ends, brings about not more but less [||22] rational practice. The problem is also, and more fundamentally, that it does not achieve its critical intent, as self-restriction to questions of means does not in fact keep research free of value implications. The reason is that alternative means to reach a given end may have different practical implications for those affected by the measures taken. For example, alternative proposals for radioactive waste disposal may impose different risks and costs on different population groups, including future generations. That is to say, decisions about means, just like decisions about ends, have a value content that is in need of both ethical reflection and democratic legitimation.

Weber's conception of a value-free, interpretive, social science breaks down as soon as one admits this implication. Once this is clearly understood, it seems almost unbelievable how uncritically a majority of contemporary social scientists still adhere to the dogma that means and ends are substantially distinct categories, so that only decisions on 'ends' are supposed to involve value judgements while the choice of 'means' is understood to be value-neutral with regard to given ends, that is, to be the legitimate business of science (cf. Ulrich, 1983, p. 72).

In order to overcome the shortcomings of both the decisionistic and the technocratic models of relating theory to practice, we need another model. Such a model will have to replace the faulty means-end dichotomy by a fundamentally complementary understanding of means and ends, that is to say, by taking them to be interdependent (cf. Ulrich, 1983, p. 222 and p. 274; 1988a, p. 147f; and 1993, p. 590). In this model, the selection of means and the selection of ends are not separable, for the rationality of either depends on the rationality of the other. Moreover, each selection has a value content of its own, although again, this value content is not independent of the value content of the other selection. It is the merit of Jürgen Habermas (1971b) to have elaborated a model that conforms to these requirements. He calls it the pragmatist model.

In the pragmatist model, neither politicians nor researchers possess an exclusive domain of genuine competence, nor can either side dominate the other. Caught in an intricate 'dialectic of potential and will' (Habermas, 1971b, p. 61), they depend on each other for the selection of both means and ends. The strict separation between their functions is replaced by a critical interaction, and the medium for this interaction is discourse. Its task is to guarantee not only an adequate translation of practical needs into technical questions, but also of technical answers into practical decisions (cf. Habermas, 1971b, p. 70f).

In order to achieve this double task, the discourse between politicians and researchers must, according to Habermas (1979), be rational (or 'rationally motivated') in the terms of his ideal model of rational discourse; that is, the discourse must be 'undistorted' and 'free from oppression'. The difficulty is, once again, that we are dealing with an ideal. Even where the discourse between politicians and experts occasionally results in an undisputed consensus, how can we ever be sure that the consensus is not merely factual rather than 'rational'? Realistically speaking, we can never be sure; for the discourse would then have to include not only the effectively involved politicians and researchers but all those who are actually or potentially concerned or affected by the decision in question, including the unborn or other parties that cannot speak for themselves; moreover, it would have to enable all of them to play a competent role. The pragmatist model thus leads us back to the fundamental concern of Critical Systems Heuristics, namely, that we need to develop a practicable and non-elitist 'critical solution' (rather than a complete 'positive solution') to the unachievable quest for securing rational practice. 
Before we turn to this idea of an at least critical solution to the problem of practical reason, let us summarize our findings with respect to a competent researcher's understanding of the relationship between theory and practice: A competent researcher will (1) examine critically the role she or he is expected to play in respect to practice; (2) analyse which model of relating theory to practice is factually assumed in her or his mandate, and which model might be most adequate to the specific situation at hand; and (3) where the appropriate answer appears to [\|23] consist in working toward a pragmatist model, a competent researcher will seek to consider all those people actually or potentially affected and, to the extent that their actual participation is feasible, will also seek to put them in a situation of competence rather than their usual situation of supposed incompetence.

\section{THE CRITICAL TURN}

The 'critical turn' is the quintessence of much of what I have tried to say in this paper. As we have seen, the quest for competence in research entails epistemological and ethical requirements that we cannot hope to satisfy completely. I am thinking particularly of requirements such as identifying all conceivable practical implications of a proposition, assuming proper boundary judgements, securing both high-quality observation and compelling argumentation, dealing properly with the practical (ethical) dimension of our 'facts and conclusions', mediating between research and practice, and facing the 'challenge of the user'.

In view of these and other requirements that we have briefly considered, the usual notion of competent research becomes highly problematic - I mean the notion that as competent researchers we ought to be able to justify our findings and conclusions in a definitive, compelling way. As an ideal, this notion of justification is certainly all right, but in practice it tempts us (or those who adopt our findings and conclusions) into raising claims to validity that no amount of research competence can possibly justify.

I suggest that we associate the quest for competence with a more credible notion of justification. First of all, let us acknowledge openly and clearly that we cannot, as a rule, sufficiently justify the results of our research. This need not mean that we cannot raise any kind of validity claims, for example regarding the quality of our observations or the rationality of our conclusions. It means, rather, that the manner in which we formulate and justify validity claims will have to change. We must henceforth qualify such claims very carefully, by explaining to what extent and how exactly they depend on assumptions or may have implications that we cannot fully justify as researchers, but can only submit to all those concerned for critical consideration, discussion, and ultimately, choice.

It is the researcher's responsibility, then, to make sure that the necessary processes of debate and choice can be made by all those concerned in as competent a way as possible. To this end, the researcher will strive to give them all the relevant information about how his or her findings came about and what they may mean to different parties. Moreover, it becomes a hallmark of competence for the researcher to undertake every conceivable effort to put those concerned in a situation of meaningful critical participation rather than of incompetence.

This is the basic credo of the critical turn that I advocate in our understanding of research competence. It amounts to what elsewhere (Ulrich, 1984, pp. 326-328, and 1993, p. 587) I 
have called a 'new ethos of justification', namely, the idea that the rationality of applied inquiry and design is to be measured not by the (impossible) avoidance of justification deficits but by the degree to which it deals with such deficits in a transparent, self-critical and self-limiting way.

Since in any case we cannot avoid justification deficits, we should seek to understand competence rather as an effort to deal self-critically with the limitations of our competence. The critical turn demands from the researcher a constant effort to be 'on the safe side' of what we can assume and claim in a critically tenable way; it demands a Socratic sense of modesty and self-limitation even where others may be willing to grant the researcher the role of expert or guarantor. Once one has grasped this meaning of the critical turn, it will become an irreversible personal commitment. Kant, the father of Critical Philosophy, said it well:

This much is certain, that whoever has once tasted critique will be ever after disgusted with all dogmatic twaddle.... (Kant, 1783, p. 190).

I invite you to 'taste critique' and to give it a firmly established place in your notion of competence! [||24]

As students of systemic research and practice, we might begin this critical effort by understanding and using the systems idea critically, in the sense of making a personal commitment to reflective research and practice. Thus conceived, the critical turn will change the way we understand the systems idea and consequently, how we use systems methodologies or any other methodologies. Rather than taking them as a ground for raising claims to rationality, or even some kind of superior 'systemic' rationality, we shall view them from now on as tools for critical reflection. In other words, we will use them more for finding questions than for finding answers.

A crucial idea that can drive the process of questioning is that of a systematic unfolding of both the empirical and the normative selectivity of (alternative sets of) boundary judgements, that is, of how the 'facts' and 'values' we recognize change when we alter the considered system (or situation) of concern. I have referred to this process earlier in this paper as a process of systematic boundary critique. Boundary critique also serves as a restraint upon unwarranted claims on the part of researchers or other people who do not employ systems methodologies (or any other methodologies) as self-critically as we might wish. If reflective research practice is not to remain dependent on the goodwill of researchers alone, it is important that other people be able to challenge their 'facts and conclusions' by making visible the boundary judgements on which they rely. The point is of course, that when it comes to these boundary judgements, researchers - whatever skills in the use of research methods, theoretical knowledge or any other kind of expertise they may possess - are in no better position than other people. Whoever claims the objective validity of some 'facts' or the rationality of some 'conclusions' without at the same time explaining the specific boundary judgements on which these claims depend, can be shown by boundary critique to be arguing on slippery grounds.

I believe that ordinary people can understand this, provided they receive an adequate introduction, and can then challenge unwarranted claims on the part of experts in an effective way, without depending on any special expert knowledge themselves. The employment of boundary judgements for critical purposes has this extraordinary power because it is a 
perfectly rational form of argumentation; it cannot be disputed simply by accusing the critic of lacking expert knowledge! For this reason, I am convinced that it is able to give not only to researchers but also to ordinary citizens a new sense of competence. I have explained this emancipatory significance of the concept of boundary judgements elsewhere in more detail (see Ulrich, 1983, pp. 301-314; 1984, pp. 341-344; 1987, p. 281f; 1993, pp. 599-605; 1996a, p. 41f; 2000a).

\section{CONCLUSION}

At the outset, I proposed (with Gadamer) that 'we understand only when we understand the question to which something is the answer'. I suggested that in order to become a more competent researcher, it might be a good idea for you to reflect on the fundamental question to which your personal quest for competence should respond.

I hope I have made it sufficiently clear that you will have to find this question yourself; nobody else can do it for you. In order to assist you in this important reflection, I have tried to offer a few topics for consideration, concerning, for example,

- your understanding of the role of methods;

- your notion of 'expertise' and of the role of the expert;

- the importance of clarifying, in each specific situation, your sense of purpose (your quest for improvement) and its sources of legitimation (the primacy of practice);

- the critical implications of the 'pragmatic maxim';

- the role of boundary judgements and the importance of systematic boundary critique;

- the role of 'facts' and 'values' and how they relate to boundary judgements;

- the requirements of high-quality observations and of compelling argumentation, and the interdependence of observational and argumentative competence; [ [|25]

- your handling of methodological pluralism;

- the problem of mediating between theory and practice; and last but not least,

- the suggestion of a 'critical turn' in your personal quest for competence in research and practice.

There are, of course, many other topics that you might consider, too; those I have chosen may perhaps serve as a starting point from which to go on to whatever additional issues you think relevant for clarifying or enriching your notion of competence.

I also proposed at the outset that for some of you, systems thinking might be part of the answer. But should it? Well, I am inclined to say, it depends: if you are ready to take the critical turn and to question the ways in which systems thinking can increase your competence, then systems thinking might indeed become a meaningful part of your personal understanding of competence. By reflecting on what might be the fundamental question to which a critical systems perspective gives part of the answer, you might begin to understand more clearly what exactly you expect to learn from studying systems thinking and how this should contribute to your personal quest for competence. 
I did not promise you that it would be easy to formulate this fundamental question. It may well be that only by hindsight, towards the end of your professional life, will you really be able to define it. In the meantime, it will be necessary to rely on some tentative formulations, and more importantly, to keep searching. Only if your mind keeps searching for the one meaningful question can you hope to recognize it when you encounter it. Eventually you will find at least a preliminary formulation that proves meaningful to you.

Perhaps you wish you had an example. Should I share my tentative question with you? At the end of this paper, I hope you are sufficiently prepared not to mistake it for your own question. I first encountered 'my' fundamental question in the year 1976 when I moved to the University of California at Berkeley to study with West Churchman, the pioneer of the systems approach whom I introduced to you earlier in this essay. Churchman used to begin his seminars with a question! He would then ask his students to explore the meaning of that question with him, and that is what I have kept doing ever since. This is what Churchman wrote up on the blackboard:

\section{Can We Secure Improvement in the Human Condition by means of the Human Intellect?}

For Churchman, each one of the underlined key expressions in the question - 'secure', 'improvement', 'human condition' and 'human intellect' - pointed to the need for a holistic understanding of the systems approach, since we cannot hope to achieve their fulfilment without a sincere quest for 'sweeping in' all aspects of an issue, that is, for 'understanding the whole system' (see Singer, 1957; Churchman, 1968a, p. 3, 1971, pp. 165-167, 1979, p. 45f, 1982a, pp. 130-132, and 1982b, pp. 12-15; Ulrich, 1994a, p. 26f). Churchman's life-long quest to understand the question thus led him to conceive of the systems approach as a heroic effort. A systems researcher or planner who is determined to live up to the implications of the question is bound to become a hero!

For me, each of the key expressions in the question points to the need for a critical turn of the systems approach, since we cannot hope to cope with their implications without a persistent critical effort to understand the ways in which we fail to be sufficiently holistic. My own quest to understand the implications of the question thus led me from my earlier 'precritical' to a 'critical' (or 'critically-holistic', as distinguished from holistic, see Ulrich, 1993) understanding of the systems approach. It made me seek for ways to bring together the two previously separate traditions of systemic and of critical thinking in what has come to be called 'critical systems thinking' (CST), a project that is far from being completed.

At least in hindsight, Churchman's question makes it easier for me to understand why I had to struggle so much to clarify my understanding of the systems idea and why I ended up with something like Critical Systems Heuristics. It is because I tried, and still try, to understand systems thinking so that it responds to that fundamental question. There is no definitive positive answer to [\|26] the question, of course; but that surely does not dispense me from struggling to gain at least some critical competence in dealing with it.

I wish you good luck in your quest for competence. 


\section{ACKNOWLEDGEMENT}

An earlier version of this paper was circulated as Working Paper No. 22 of the Lincoln School of Management, University of Lincolnshire and Humberside, Lincoln, UK (Ulrich, 1998a). The author is grateful to the research students of the School for many stimulating discussions, and to its Centre for Systems Research for offering him the Visiting Professorship that has made this work possible.

\section{REFERENCES}

Ackoff, R.L. (1974). Redesigning the Future: A Systems Approach to Societal Problems. Wiley, New York.

Ackoff, R.L. (1981). Creating the Corporate Future. Wiley, New York.

Ackoff, R.L., and Emery, F.E. (1972). On Purposeful Systems. Tavistock, London, UK, and Aldine-Atherton, Chicago, Ill.

Ammann, P., Binder, J., and Ulrich, W. (1993). Armut, Arbeitsmarkt und Bildung im Kanton Bern. Die Volkswirtschaft, 66, No. 1, January, pp. 52-56.

Apel, K.O. (1967-70). Introductions to the German translations of Charles S. Peirce, Schriften, 2 vols., K.O. Apel, ed. Suhrkamp, Frankfurt am Main, Germany, Vol. 1, 1967, and Vol. 2, 1970.

Apel, K.O. (1972). The a priori of communication and the foundation of the humanities. Man and World, 5, 337. Partly reprinted in F.R. Dallmayr and T.A. McCarthy, eds., Understanding and Social Inquiry, University of Notre Dame Press, Notre Dame, Indianapolis, and London, UK, pp. 292-315.

Apel, K.O. (1976a). Sprechakttheorie und transzendentale Sprachpragmatik - Zur Frage ethischer Normen. In K.-O. Apel, ed., Sprachpragmatik und Philosophie, Suhrkamp, Frankfurt am Main, Germany, pp. 10-173.

Apel, K.O. (1976b). Sprachpragmatik und Philosophie. Suhrkamp, Frankfurt am Main, Germany.

Checkland, P.B. (1981). Systems Thinking, Systems Practice.Wiley, Chichester, UK, and New York.

Checkland, P.B. (1985). From optimizing to learing: a development of systems thinking for the 1990s. Journal of the Operational Research Society, 36, 757-767.

Churchman, C.W. (1968a). Challenge to Reason. McGraw-Hill, New York.

Churchman, C.W. (1968b). The Systems Approach. Delacorte Press, New York (2 ${ }^{\text {nd }}$ rev. ed., Dell, New York, 1979).

Churchman, C.W. (1970). Operations research as a profession. Management Science, 17 (No.2), B37-53.

Churchman, C.W. (1971). The Design of Inquiring Systems. Basic Books, New York.

Churchman, C.W. (1979). The Systems Approach and Its Enemies. Basic Books, New York.

Churchman, C.W. (1982a). An appreciation of Edgar Arthur Singer, Jr. In C.W. Churchman, Thought and Wisdom, Intersystems, Seaside, Calif., pp. 116-135.

Churchman, C.W. (1982b). Thought and Wisdom. Intersystems, Seaside, Calif.

Collingwood, R.G. (1946). The Idea of History. Clarendon Press, Oxford, UK.

de Zeeuw, G. (1992). Soft knowledge accumulation, or the rise of competence. Systems Practice, 5, 193-214.

de Zeeuw, G. (1995). Values, science and the quest for demarcation. Systems Research, 12, 15-24.

de Zeeuw, G. (1996). Second Order Organizational Research. Working Papers No. 7, Lincoln School of Management, University of Lincolnshire and Humberside, Lincoln, UK.

Flood, R.L., and Jackson, M.C. (1991). Creative Problem Solving: Total Systems Intervention, Wiley, Chichester.

Gadamer, H.G. (1975). Wahrheit und Methode. $4^{\text {th }}$ ed., J.C.B. Mohr (Paul Siebeck), Tübingen, Germany (orig. 1960; engl. transl. Truth and Method, $2^{\text {nd }}$ rev. ed., Continuum Publishing, New York and London, 1993).

Habermas, J. (1970). Towards a theory of communicative competence. Inquiry, 13, 360-375.

Habermas, J. (1971a). Knowledge and Human Interests. Beacon Press, Boston, Mass. 
Habermas, J. (1971b). Towards a Rational Society. Beacon Press, Boston, Mass.

Habermas, J. (1973). Wahrheitstheorien. In H. Fahrenbach, ed., Wirklichkeit und Reflexion, Walter Schulz zum 60. Geburtstag, Neske, Pfullingen, Germany, pp. 211-265.

Habermas, J. (1979). What is universal pragmatics? In J. Habermas, Communication and the Evolution of Society, Beacon Press, Boston, Mass., pp. 1-68.

Habermas, J. (1984-87). The Theory of Communicative Action, 2 vols. (Vol. 1, 1984; Vol. 2, 1987). Beacon Press, Boston, Mass., and Polity, Cambridge, UK.

Jackson, M.C. (1987). Present positions and future prospects in management science. Omega, International Journal of Management Science, 15, 455-466.

Jackson, M.C. (1990). Beyond a system of system methodologies. Journal of the Operational Research Society, 41, 657-668.

Jackson, M.C. (1991). Systems Methodology for the Management Sciences. Wiley, Chichester.

Jackson, M.C. (1997). Pluralism in systems thinking and practice. In J. Mingers and A. Gill, Multimethodology: The Theory and Practice of Combining Management Science Methodologies, Wiley, Chichester, UK, pp. 237-257.

Jackson, M.C. (1999). Toward coherent pluralism in management science. Journal of the Operational Research Society, 50, 12-22. [||27]

Jackson, M.C., and Keys, P. (1984). Towards a system of systems methodologies. Journal of the Operational Research Society, 35, 473-486.

Kant, I. (1783). Prolegomena to Any Future Metaphysics, 1st ed., transl. by P. Carus, rev. ed. by L.W. Beck. Liberal Arts Press, New York, 1951.

Kant, I. (1786). Groundwork of the Metaphysic of Morals, transl. and analyzed by H.J. Paton. Harper Torchbooks, New York, 1964.

Kant, I. (1787). Critique of Pure Reason, 2nd ed., transl. by N.K. Smith. St. Martin's Press, New York, 1965.

Kant, I. (1788). Critique of Practical Reason and Other Writings in Moral Philosophy, transl. and ed. with an Introduction by L.W. Beck. University of Chicago Press, Chicago, Ill., 1949.

Linstone, H.A. (1984). Multiple Perspectives for Decision Making. North-Holland, New York.

Linstone, H.A. (1989). Multiple perspectives: Concept, applications and user guidelines. Systems Practice, 2 , 307-331.

Luhmann, N. (1984). Soziale Systeme: Grundriss einer allgemeinen Theorie, Suhrkamp, Frankfurt am Main, Germany.

Luhmann, N. (1997). Die Gesellschaft der Gesellschaft. 2 vols., Suhrkamp, Frankfurt am Main, Germany.

Midgley, G. (1992a). The sacred and the profane in critical systems thinking. Systems Practice, 5, 5-16.

Midgley, G. (1992b). Pluralism and the legitimation of systems science. Systems Practice, 5, 147-172.

Midgley, G. (1994). Ecology and the poverty of humanism: a critical systems perspective. Systems Research, 11, 67-76.

Midgley, G. (1996a). The ideal of unity and the practice of pluralism in systems science. In R.L. Flood and N.R.A. Romm, eds., Critical Systems Thinking: Current Research and Practice, Plenum, New York, pp. 2536.

Midgley, G. (1996b). What is this thing called critical systems thinking? In R.L. Flood and N.R.A. Romm, eds., Critical Systems Thinking: Current Research and Practice, Plenum, New York, pp. 61-71.

Midgley, G. (1997). Mixing methods: developing systemic intervention. In J. Mingers and A. Gill, eds., Multimethodology: The Theory and Practice of Combining Management Science Methodologies, Wiley, Chichester, pp. 249-290.

Midgley, G., Munlo, I., and Brown, M. (1998). The theory and practice of boundary critique: developing housing services for older people. Journal of the Operational Research Society, 49, 467-478.

Mingers, J. (1997). Towards critical pluralism. In J. Mingers and T. Gill, eds., Multimethodology: The Theory and Practice of Combining Management Science Methodologies, Wiley, Chichester, pp. 407-444.

Mingers, J., and Brocklesby, J. (1996). Multimethodology: Towards a framework for critical pluralism. Systemist, 18, 101-132. 
Mingers, J., and Gill, T. (1997). Multimethodology: The Theory and Practice of Combining Management Science Methodologies. Wiley, Chichester.

Oliga, J.C. (1988). Methodological foundations of systems methodologies. Systems Practice, 1, 87-112.

Ormerod, R. (1997). Mixing methods in practice: a transformation-competence perspective. In J. Mingers and T. Gill, eds., Multimethodology: The Theory and Practice of Combining Management Science Methodologies, Wiley, Chichester, pp. 29-58.

Peirce, Ch.S. (1878). How to make our ideas clear. In Collected Papers, Vol. V. Ch. Hartshorne and P. Weiss, eds., Harvard Univ. Press, Cambridge, Mass., 2nd ed. 1969, pp. 248-271.

Popper, K.R. (1959). The Logic of Scientific Discovery. Hutchison, London.

Popper, K.R. (1963). Conjectures and Refutations: The Growth of Scientific Knowledge. Routledge \& Kegan Paul, London.

Popper, K.R. (1972). Objective Knowledge: An Evolutionary Approach. Clarendon Press, Oxford, UK.

Singer, E.A. Jr. (1959). Experience and Reflection, C.W. Churchman, ed. University of Pennsylvania Press, Philadelphia, Penn.

Strawson, P.F. (1964). ‘Truth’. In G. Pitcher, ed., Truth, Prentice-Hall, Englewood Cliffs, N.J., pp. 32-53.

Ulrich, W. (1980). The metaphysics of design: A Simon-Churchman 'debate'. Interfaces, 10 (No. 2), 35-40. Reprinted in a slightly expanded version as 'The metaphysics of social systems design' in J.P. van Gigch, ed., Decision Making about Decision Making: Metamodels and Metasystems, Abacus Press, Cambridge, Mass., and Tunbridge Wells, Kent, UK, pp. 219-226.

Ulrich, W. (1981). Systemrationalität und praktische Vernunft - Gedanken zum Stand des Systemansatzes. Translator's introduction to C.W. Churchman, Der Systemansatz und seine 'Feinde', Haupt, Bern, Switzerland, and Stuttgart, Germany, pp. 7-37.

Ulrich, W. (1983). Critical Heuristics of Social Planning: A New Approach to Practical Philosophy, Haupt, Bern, Switzerland, and Stuttgart, Germany; Paperback reprint edition, Wiley, New York, 1994.

Ulrich, W. (1984). Management oder die Kunst, Entscheidungen zu treffen, die andere betreffen. Die Unternehmung, Schweizerische Zeitschrift für betriebswirtschaftliche Forschung und Praxis, 38, 326-346.

Ulrich, W. (1985). The way of inquiring systems. Review of 'The Design of Inquiring Systems' by C. West Churchman (Basic Books, New York, 1971), Journal of the Operational Research Society, 36, 873-876.

Ulrich, W. (1987). Critical heuristics of social systems design. European Journal of Operational Research, 31, 276-283. Reprinted in M.C. Jackson, P.A. Keys and S.A. Cropper, eds., Operational Research and the Social Sciences, Plenum Press, New York, 1989, pp. 79-87, and in R.L. Flood and M.C. Jackson, eds., Critical Systems Thinking: Directed Readings, Wiley, New York, 1991, pp. 103-115.

Ulrich, W. (1988a). Systems thinking, systems practice, and practical philosophy: A programme of research. Systems Practice, 1, 137-163. Reprinted in R.L. Flood and M.C. Jackson, eds., Critical Systems Thinking: Directed Readings, Wiley, New York, 1991, pp. 245-268. [||28]

Ulrich, W. (1988b). C. West Churchman - 75 Years. Guest editorial to the Special Issue in honour of C.W. Churchman's 75 years. W. Ulrich, ed., Systems Practice, 1, No. 4, pp. 341-350.

Ulrich, W. (1988c). Churchman's 'process of unfolding' - Its significance for policy analysis and evaluation. Systems Practice, 1, 415-428.

Ulrich, W. (1989). Zum Stand der schweizerischen Armutsforschung. Neue Zürcher Zeitung, 210, No. 168 (Zurich, Switzerland), 22/23 July, p. 21.

Ulrich, W. (1993). Some difficulties of ecological thinking, considered from a critical systems perspective: A plea for critical holism. Systems Practice, 6, 583-611.

Ulrich, W. (1994a). Can we secure future-responsive management through systems thinking and design? Interfaces, 24, No. 4, 26-37.

Ulrich, W. (1994b). Armut im Alter. In H.D. Schneider, ed., Gerontologie und Ökonomie, Bargezzi, Bern, Switzerland, pp. 106-123.

Ulrich, W. (1995). Critical Systems Thinking for Citizens: A Research Proposal. Research Memorandum No. 10, Centre for Systems Studies, University of Hull, Hull, UK, 28 November 1995.

Ulrich, W. (1996a). A Primer to Critical Systems Heuristics for Action Researchers. Centre for Systems Studies, University of Hull, Hull, UK, 31 March 1996. 
Ulrich, W. (1996b). Critical systems thinking for citizens. In R.L. Flood and N.R.A. Romm, eds., Critical Systems Thinking: Current Research and Practice, Plenum, New York, pp. 165-178.

Ulrich, W. (1997). Critical systems thinking for citizens, or systems thinking as if people mattered. In G.E. Lasker, ed., Advances in Sociocybernetics and Human Development, Vol. III, The International Institute for Advanced Studies in Systems Research and Cybernetics, Windsor, Ontario, pp. 28-32.

Ulrich, W. (1998a). If Systems Thinking is the Answer, What is the Question? The Quest for Competence in Systemic Research and Practice, Working Paper No. 22, Lincoln School of Management, University of Lincolnshire and Humberside, Lincoln, UK.

Ulrich, W. (1998b). Systems Thinking as if People Mattered: Critical Systems Thinking for Citizens and Managers. Working Paper No. 23, Lincoln School of Management, University of Lincolnshire and Humberside, Lincoln, UK.

Ulrich, W. (1999). An appreciation of C. West Churchman, with an extensive bibiography from 1938 to 2000. Website Luminaries of the Systems Approach of the International Society for the Systems Sciences (ISSS), Ponoma, Calif., 29 August 1999, last updated 5 January 2000, http://www.isss.org/lumCWC.htm.

Ulrich, W. (2000a). Reflective practice in the civil society: The contribution of critically systemic thinking. Reflective Practice, 1 (No. 2, July).

Ulrich, W. (2000b). Critically Systemic Discourse, Emancipation, and the Public Sphere. Working Paper No. 41. Faculty of Business and Management, University of Lincolnshire and Humberside, Lincoln and Hull, UK (September).

Ulrich, W., and Binder, J. (1992). Armut im Kanton Bern. Medienbericht, Gesundheits- und Fürsorgedirektion des Kantons Bern, Bern, Switzerland.

Ulrich, W., and Binder, J. (1998). Armut erforschen. Verlag Seismo Sozialwissenschaften und Gesellschaftsfragen, Zurich, Switzerland.

Weber, M. (1991). From Max Weber: Essays in Sociology. H.H. Gerth and C. Wright Mills, eds., Routledge, London (orig. 1948).

White, L., and Taket, A. (1994). The death of the expert. Journal of the Operational Research Society, 45, 733-748.

White, L., and Taket, A. (1997). Critiquing multimethodology as metamethodology: working towards pragmatic pluralism. In J. Mingers and T. Gill, eds., Multimethodology: The Theory and Practice of Combining Management Science Methodologies, Wiley, Chichester, pp. 379-405. 